\title{
Characteristics of children diagnosed with type 1 diabetes before vs after 6 years of age in the TEDDY cohort study
}

\author{
Jeffrey P. Krischer ${ }^{1}$ (D) Xiang Liu $^{1}$ (D) A Åke Lernmark ${ }^{2}$ (D) - William A. Hagopian ${ }^{3}$ (D) Marian J. Rewers $^{4}$ (D) \\ Jin-Xiong She ${ }^{5}$ (D) Jorma Toppari ${ }^{6,7}$ (D) Anette-G. Ziegler $^{8}$ (D) Beena Akolkar ${ }^{9}$ (D) on behalf of the TEDDY Study \\ Group
}

Received: 26 February 2021 / Accepted: 29 April 2021 / Published online: 22 July 2021

(C) The Author(s), under exclusive licence to Springer-Verlag GmbH Germany, part of Springer Nature 2021

\begin{abstract}
Aims/hypothesis Prognostic factors and characteristics of children diagnosed with type 1 diabetes before 6 years of age were compared with those diagnosed at 6-13 years of age in the TEDDY study.

Methods Genetically high-risk children $(n=8502)$ were followed from birth for a median of 9.9 years; $328(3.9 \%)$ were diagnosed with type 1 diabetes. Cox proportional hazard model was used to assess the association of prognostic factors with the risk of type 1 diabetes in the two age groups.

Results Children in the younger group tended to develop autoantibodies earlier than those in the older group did (mean age 1.5 vs 3.5 years), especially insulin autoantibodies (IAA), which developed earlier than GAD autoantibodies (GADA). Children in the younger group also progressed to diabetes more rapidly than the children in the older group did (mean duration 1.9 vs 5.4 years). Children with autoantibodies first appearing against insulinoma antigen-2 (IA-2A) were found only in the older group. The significant diabetes risk associated with the country of origin in the younger group was no longer significant in the older group. Conversely, the diabetes risk associated with HLA genotypes was statistically significant also in the older group. Initial seroconversion after and before 2 years of age was associated with decreased risk for diabetes diagnosis in children positive for multiple autoantibodies, but the diabetes risk did not decrease further with increasing age if initial seroconversion occurred after age 2. Diabetes risk associated with the minor alleles of rs1004446 (INS) was decreased in both the younger and older groups compared with other genotypes (HR 0.67). Diabetes risk was significantly increased with the minor alleles of rs2476601 (PTPN22) (HR 2.04 and 1.72), rs428595 (PPIL2) (HR 2.13 and 2.10), rs113306148 (PLEKHA1) (HR 2.34 and 2.21) and rs73043122 (RNASET2) (HR 2.31 and 2.54) (HR values represent the younger and older groups, respectively).

Conclusions/interpretations Diabetes at an early age is likely to be preceded by IAA autoantibodies and is a more aggressive form of the disease. Among older children, once multiple autoantibodies have been observed there does not seem to be any association between progression to diabetes and the age of the child or family history.

Trial registration ClinicalTrials.gov identifier: NCT00279318.
\end{abstract}

Keywords Autoimmunity · Type 1 diabetes

Jeffrey P. Krischer

jeffrey.krischer@epi.usf.edu

1 Health Informatics Institute, Morsani College of Medicine, University of South Florida, Tampa, FL, USA

2 Department of Clinical Sciences, Lund University/CRC, Skåne University Hospital SUS, Malmo, Sweden

3 Pacific Northwest Diabetes Research Institute, Seattle, WA, USA

4 Barbara Davis Center for Childhood Diabetes, University of Colorado, Aurora, CO, USA
5 Center for Biotechnology and Genomic Medicine, Augusta University, Augusta, GA, USA

6 Department of Pediatrics, Turku University Hospital, Turku, Finland

7 Institute of Biomedicine, Research Centre for Integrated Physiology and Pharmacology, and Population Research Centre, University of Turku, Turku, Finland

8 Institute of Diabetes Research, Helmholtz Zentrum München, and Klinikum rechts der Isar, Technische Universität München, and Forschergruppe Diabetes e.V, Neuherberg, Germany

9 National Institute of Diabetes \& Digestive \& Kidney Diseases, Bethesda, MD, USA 


\section{Research in context}

\section{What is already known about this subject?}

- Diabetes-related insulin autoantibodies (IAA) appear first in very young children whereas GAD autoantibodies (GADA) usually only appear after the age of 5 years. After the age of 5 years, IAA is rarely the first autoantibody to appear

\section{What is the key question?}

- In addition to differences in the way that diabetes-related autoimmunity arises as children grow older, are there also different risk factors and rates of progression for diabetes that are associated with age?

What are the new findings?

- The association of country of origin on diabetes risk found in the younger group declined in the older age group, while the genotypic association significantly increased

- After age 2 years at seroconversion there was no longer a decreasing risk for diabetes in children positive for multiple autoantibodies associated with the age of initial seroconversion

- After multiple autoantibodies were observed, there was not a discernible difference in risk by family history of type 1 diabetes

\section{How might this impact on clinical practice in the foreseeable future?}

- This study adds to the growing body of evidence that type 1 diabetes is not a single, homogeneous disease. It differs in its presentation and, perhaps, aetiology. Much of the observed difference in the relationships between genes and exposures is explained by the age at appearance of autoantibodies, establishing that factors associated with diabetes risk need to be conditioned on age to be properly understood

$\begin{array}{ll}\text { Abbreviations } \\ \text { FDR } & \text { First-degree relative } \\ \text { GADA } & \text { GAD autoantibodies } \\ \text { IAA } & \text { Insulin autoantibodies } \\ \text { IA-2A } & \text { Insulinoma antigen-2 } \\ \text { PH } & \text { Proportional hazard } \\ \text { TEDDY } & \text { The Environmental Determinants } \\ & \text { of Diabetes in the Young }\end{array}$

\section{Introduction}

The Environmental Determinants of Diabetes in the Young (TEDDY) study has enrolled and followed a cohort of 8676 infants at elevated genetic risk for autoimmune type 1 diabetes from 3 months of age [1-3]. TEDDY is designed to follow children for 15 years. The characteristics of children progressing to type 1 diabetes during the first 6 years of age (the first third of the planned follow-up period) has been published [4], and there is now additional follow-up for the middle third of the planned follow-up period, i.e., through to 12 years of age. This paper describes the characteristics of children developing autoimmunity and type 1 diabetes during their second 6 years of life and seeks to identify differences in the pattern of islet autoantibody development and the changing relationship between previously identified risk factors for autoantibodies and type 1 diabetes endpoints. The aim is to explore whether the younger cohort developing type 1 diabetes differs from the older cohort, suggesting the emergence of a different form of type 1 diabetes in children as they get older.

The age at the first appearance of islet autoantibodies has been shown to be related to which autoantibody appears first, which has, in turn, been linked to specific genotypic subtypes and associated environmental exposures [4]. It was also noted that the incidence of insulin autoantibodies (IAA) as the firstappearing autoantibody during the first 6 years of life, declined with age, almost disappearing, while the incidence of GAD autoantibodies (GADA), as the first-appearing autoantibody, increased and remained stable throughout follow-up [5]. The changing incidence of the first-appearing autoantibody, as children age, signifies a possible difference in both the aetiology and the pathogenesis of type 1 diabetes. Therefore, this study explores differences in characteristics of children who progressed to diabetes among the younger $<6$ years of age cohort, presumably arising from those who predominantly developed IAA first and compares them with the characteristics of children who progressed to diabetes among the 6-12 years of age cohort, presumably arising from those who predominantly developed GADA first, with particular emphasis on factors that were prognostic for disease initiation (aetiology) and progression (pathogenesis) specific to these age intervals. 


\section{Methods}

\section{Participants}

TEDDY is a prospective cohort study funded by the National Institutes of Health with the primary goal of identifying environmental causes of type 1 diabetes. It includes six clinical research centres - three in the US (Colorado, Georgia/Florida and Washington State) and three in Europe (Finland, Germany and Sweden). Detailed study design and methods have been previously published [1-3]. Written informed consents was obtained for all study participants from a parent or primary caretaker, separately, for genetic screening and participation in the prospective follow-up. The high-risk genotypes for participants screened from the general population were as follows: $D R B 1 * 04$ $D Q A 1 * 03-D Q B 1 * 03: 02 / D R B 1 * 03-D Q A 1 * 05-D Q B 1 * 02: 01$ (DR3/4), DRB1*04-DQA1*03-DQB1*03:02/DRB1*04$D Q A 1 * 03-D Q B 1 * 03: 02$ (DR4/4), DRB1*04-DQA1*03$D Q B 1 * 03: 02 / D R B 1 * 08-D Q A 1 * 04-D Q B 1 * 04: 02$ (DR4/8) and $D R B 1 * 03-D Q A 1 * 05-D Q B 1 * 02: 01 / D R B 1 * 03-D Q A 1 * 05$ $D Q B 1 * 02: 01$ (DR3/3). Additional genotypes were included for first-degree relatives (FDRs) of an individual with type 1 diabetes: $D R B 1 * 04-D Q A 1 * 03-D Q B 1 * 03: 02 / D R B 1 * 04-D Q A 1 * 03-$ $D Q B 1 * 02: 02$ (DR4/4b), DRB1*04-DQA1*03-DQB1*03:02/ $D R B 1 * 01-D Q A 1 * 01-D Q B 1 * 05: 01$ (DR4/1), DRB1*04$D Q A 1 * 03-D Q B 1 * 03: 02 / D R B 1 * 13-D Q A 1 * 01-D Q B 1 * 06: 04$ (DR4/13), DRB1*04-DQA1*03-DQB1*03:02/DRB1*09$D Q A 1 * 03-D Q B 1 * 03: 03$ (DR4/9) and $D R B 1 * 03-D Q A 1 * 05$ $D Q B 1 * 02: 01 / D R B 1 * 09-D Q A 1 * 03-D Q B 1 * 03: 03$ (DR3/9). The HLA-DR-DQ genotype abbreviations shown in parentheses will be used throughout this paper. Genotyping was confirmed by reverse blot hybridisation at the central HLA Reference Laboratory at Roche Molecular Systems, Oakland, CA [3], along with the INS-23Hph1 (rs689), CTLA4 T17A (rs231775) and PTPN22 R620W (rs2476601) SNP primer pairs. The study was approved by local institutional review or ethics boards and is being monitored by an external evaluation committee formed by the National Institutes of Health.

SNP genotyping was performed by the Center for Public Health Genomics at the University of Virginia using the Illumina Immunochip, which is a custom array for genotyping SNPs selected from regions of the human genome firmly associated with autoimmune diseases [6]. The final selection containing approximately 186,000 SNPs in 186 regions for 12 autoimmune diseases was decided by the Immunochip Consortium. TEDDY previously examined whether any of 41 non-HLA SNPs previously shown to be associated with type 1 diabetes conferred risk for islet autoimmunity [7].

\section{Islet autoantibodies}

Islet autoantibodies to insulin (IAA), GAD (GADA) or insulinoma antigen-2 (IA-2A) were measured in two laboratories by radiobinding assays. In the USA, all sera were assayed at the Barbara Davis Center for Childhood Diabetes at the University of Colorado Denver; in Europe, all sera were assayed at the University of Bristol, UK. Both laboratories demonstrated high sensitivity and specificity as well as concordance [8]. All positive islet autoantibody samples and $5 \%$ of the negative samples were re-tested in the other reference laboratory and deemed confirmed if concordant. Persistent islet autoimmunity was defined as confirmed positive IAA, GADA or IA-2A in at least two consecutive samples. Zinc transporter autoantibodies (ZnT8A) were measured in samples positive for one of the other autoantibodies.

\section{Statistical methods}

Characteristics of $<6$ year olds who progressed to diabetes diagnosis were compared with those of children between 6 and 12 years of age who progressed to diabetes diagnosis by non-parametric (Wilcoxon rank sum) tests for continuous variables and Pearson's $\chi 2$ tests for categorical variables. Multiple Cox proportional hazard ( $\mathrm{PH}$ ) models were applied to examine factors related to the risk of diabetes previously published in the TEDDY study [5, 7, 9-12] with and without the adjustment of age at onset of multiple autoantibodies as a time-dependent covariate. The associations between the factors and the risk of type 1 diabetes during the first 6 years of age and in the range of 6-12 years of age were examined, as was the interaction between the factors and the dichotomised time variable (the two age intervals) treated as time-dependent covariates [13]. The magnitudes of the associations were described by HRs with $95 \%$ CIs. Comparisons between the younger and older HRs were conducted by testing whether the ratio of the two HRs differed from 1 based on Wald tests. Adjustments for population stratification were made by using the top two principal components from the Immunochip SNP data as covariates in the Cox PH models [14]. Hazard rates of progression to type 1 diabetes since the onset of multiple autoantibodies stratified by the age at initial seroconversion were calculated assuming exponential survival distribution. Data were analysed using the Statistical Analysis System software (version 9.4; SAS Institute, Cary, NC). Two-tailed $p$ values less than 0.05 were considered to be statistically significant. No adjustment for type 1 error was made for multiple comparisons except in the context of the multiple Cox regression model.

\section{Results}

From September 2004 until February 2010, TEDDY enrolled 8676 children at birth, of whom 174 were excluded because of HLA ineligibility or indeterminate autoantibody status, leaving 8502 in the analysis. Children were followed quarterly for progression to diagnosis of diabetes. Follow-up of children with one or more islet autoantibodies continued on this 
schedule, whereas children who were autoantibody negative were followed semi-annually after 4 years of age. The median (IQR) age at last follow-up was $9.9(8.1-11.5)$ years and the age range was $8-14$ years.

As of 30 November 2018, 328 children (3.9\%) had developed type 1 diabetes; $168(2.0 \%)$ before 6 years of age and $160(1.9 \%)$ at or after 6 years of age (Table 1$)$. The incidence of type 1 diabetes remained fairly stable (Fig. 1), but the cumulative incidence differed by enrolment site $(p=0.0009$, Fig. 2). However, the excess risk associated with enrolment from Germany may be the consequence of the high proportion of FDRs enrolled (36.1\%) compared with all the other TEDDY sites (9.2\%). By 10 years of age, children from Germany and Finland had a comparable cumulative diabetes risk, as did children from Sweden and the US, but the risk in Germany and Finland remained higher than in the other two countries. The difference in geographic distribution of new type 1 diabetes patients reflects a drop in the proportion from Finland and Germany and an increase in the US while the proportion remained unchanged in Sweden $(p=0.001)$.

The HLA distribution of diabetes patients was also different with an increase among those who were DR $4 / 4$ in the older age group and a corresponding decrease among those who were DR3/3 or had FDR-specific HLA genotypes ( $p=$ $0.005)$. Those who were diagnosed with diabetes at 6 years of age or older developed a persistent confirmed autoantibody at an older mean age than those who became autoantibody positive before the age of 6 ( 3.5 vs 1.5 years, $p<0.001)$. The mean duration of time between the first-appearing autoantibody and the diabetes diagnosis was also much longer (5.4 years vs 1.9 years, $p<0.001$ ) in older than in younger children. Similar patterns were observed when considering the appearance of multiple persistent confirmed autoantibodies (3.9 years and 1.8 years) and time until progression to diabetes (4.9 years vs 1.6 years) $(p<0.001$ for both).

The pattern of first-appearing autoantibody was also significantly different between those who were diagnosed with diabetes before 6 years of age and those who were diagnosed older $(p=0.001)$. As might be expected, the percentage of those with GADA as the first-appearing autoantibody was higher in the older group (26.9\% vs $18.5 \%$ ) and the percentage of those presenting with IAA first was much higher in the younger group ( $44.6 \%$ vs $28.1 \%$ ). Interestingly, no children in the younger group presented with IA-2A as the first-appearing autoantibody, but $10(6.3 \%)$ among the older children did. In six of these individuals, ZnT8A autoantibodies were also present when IA-2A autoantibodies were detected.

No autoantibodies were detected in $36(11.0 \%)$ of the children diagnosed with diabetes. The median (IQR) interval between the last autoantibody testing and the diabetes diagnosis in the 22 children from the older age group was 8.6 years (7.0-8.9) suggesting that autoantibody positivity at diagnosis, or long before it, was unknown because of lack of testing and poor protocol compliance. Among the 14 who developed type 1 diabetes in the younger age group without detected autoantibodies, the median (IQR) interval was 2.3 years $(0.85-2.86)$. There were six children under 6 years of age whose last autoantibody test was negative within 2 years preceding their diabetes diagnosis. Whole genome sequencing was available for three, one of whom had a variant in the HNF1A gene (rs762703502) associated with maturity-onset diabetes of the young, type 3 .

Autoantibodies at the time of diabetes diagnosis showed that a higher per cent were IAA negative prior to diagnosis among the older group (28.8\%) compared with the younger group (13.1\%), $p<0.001$. A lower per cent were ZnT8A negative in the older group (34.4\%) compared with in the younger group $(61.9 \%)(p<0.001)$.

The incidence of diabetic ketoacidosis (DKA) at diagnosis was marginally lower $(p=0.046)$ in the older age group compared with in the younger group, but the proportion who were symptomatic or not at diagnosis was not different.

The HRs from a multivariate $\mathrm{PH}$ model of risk factors published by the TEDDY study also revealed some differences in their association with diabetes comparing the two age groups (Table 2). The risk of type 1 diabetes in families with a mother who had type 1 diabetes significantly increased compared with families without an affected relative, in the older age group (HR $2.64,95 \%$ CI 1.36, 5.12, $p=0.004$ ) whereas it was not a significant risk factor in the younger age group (HR 1.51, 95\% CI $0.75,3.05, p=0.249)$. However, this difference in HRs was not statistically significant, reflecting the wide confidence intervals of the individual HRs. Also, the risk of diabetes associated with DR4/4 vs DR3/3 was significant in the older (HR 4.16, 95\% CI $1.99,8.69, p<0.001$ ), but not in the younger (HR 1.26, $95 \%$ CI $0.65,2.44, p=0.496$ ) age group. This increase in HRs was statistically significant at $p=0.018$, suggesting that the DR4/ 4 genotype has a larger role in development of type 1 diabetes in older than in younger individuals. Conversely, in the older age group, the type 1 diabetes risk associated with children from Finland and Germany significantly declined (HR 3.20, 95\% CI $1.88,5.45, p<0.001$ to HR $1.26,95 \%$ CI $0.73,2.18, p=0.416$ and HR $2.19,95 \%$ CI 1.27, 3.78, $p=0.005$ to HR $0.56,95 \% \mathrm{CI}$ $0.25,1.27, p=0.167$, respectively) ( $p=0.005$ and $p=0.007$, respectively) compared with children from the US. Other risk factors were, or were not, statistically significant in both age groups. However, the HRs comparing the two groups were not significantly different.

Once multiple autoantibodies were observed, the rate of progression to type 1 diabetes decreased as the age at initial seroconversion increased ( $p=0.0003$, Fig. 3a). Children under 2 years of age at initial seroconversion progressed much more rapidly to type 1 diabetes once multiple autoantibodies were detected (hazard rate of 0.19) through 6 years of followup. If diabetes did not develop during this interval of time, the rate of progression from multiple autoantibodies to type 1 diabetes (hazard rate 0.115 ) was approximately the same as 
Table 1 Characteristics of TEDDY children

\begin{tabular}{|c|c|c|c|c|}
\hline Characteristic & $\begin{array}{l}\text { No type } 1 \\
\text { diabetes } \\
(n=8174)\end{array}$ & $\begin{array}{l}\text { Type } 1 \text { diabetes before } \\
6 \text { years } \\
\text { of age }(n=168)\end{array}$ & $\begin{array}{l}\text { Type } 1 \text { diabetes } \\
\geq 6 \text { years } \\
\text { of age }(n=160)\end{array}$ & $\begin{array}{l}p \\
\text { value }^{a}\end{array}$ \\
\hline \multicolumn{5}{|l|}{ Country } \\
\hline USA & $3515(43.0)$ & $47(28.0)$ & $65(40.6)$ & \multirow[t]{4}{*}{0.001} \\
\hline Finland & $1711(20.9)$ & $54(32.1)$ & $38(23.8)$ & \\
\hline Germany & $542(6.6)$ & $25(14.9)$ & $7(4.4)$ & \\
\hline Sweden & $2406(29.4)$ & $42(25.0)$ & $50(31.3)$ & \\
\hline \multicolumn{5}{|l|}{ Family history } \\
\hline FDR: Mother & $315(3.9)$ & $10(6.0)$ & $13(8.1)$ & \multirow[t]{4}{*}{0.106} \\
\hline FDR: Father & $408(5.0)$ & $30(17.9)$ & $14(8.8)$ & \\
\hline FDR: Sibling & $123(1.5)$ & $11(6.5)$ & $12(7.5)$ & \\
\hline $\begin{array}{l}\text { General } \\
\text { population }\end{array}$ & 7328 (89.7) & $117(69.6)$ & $121(75.6)$ & \\
\hline \multicolumn{5}{|l|}{ Sex } \\
\hline Male & $4142(50.7)$ & $85(50.6)$ & $84(52.5)$ & \multirow[t]{2}{*}{0.730} \\
\hline Female & $4032(49.3)$ & $83(49.4)$ & $76(47.5)$ & \\
\hline \multicolumn{5}{|l|}{ HLA genotype } \\
\hline $\mathrm{DR} 3 / 4$ & $3140(38.4)$ & $96(57.1)$ & $82(51.3)$ & \multirow[t]{5}{*}{0.005} \\
\hline DR4/4 & $1601(19.6)$ & $20(11.9)$ & $40(25.0)$ & \\
\hline DR4/8 & $1423(17.4)$ & $21(12.5)$ & $24(15.0)$ & \\
\hline $\mathrm{DR} 3 / 3$ & $1754(21.5)$ & $18(10.7)$ & $10(6.3)$ & \\
\hline FDR-specific ${ }^{b}$ & $256(3.1)$ & $13(7.7)$ & $4(2.5)$ & \\
\hline \multicolumn{5}{|c|}{ Probiotics introduction age } \\
\hline$\geq 28$ days & 7615 (93.2) & $153(91.1)$ & $151(94.4)$ & \multirow[t]{2}{*}{0.251} \\
\hline$<28$ days & $559(6.8)$ & $15(8.9)$ & $9(5.6)$ & \\
\hline \multicolumn{5}{|c|}{ Weight $z$ score at 12 months } \\
\hline$n$ & 7460 & 161 & 149 & \\
\hline Mean (SD) & $-0.1(1.0)$ & $-0.0(1.1)$ & $0.0(1.0)$ & \\
\hline Median (IQR) & $-0.1(-0.8-0.6)$ & $0.0(-0.8-0.7)$ & $-0.0(-0.6-0.7)$ & 0.582 \\
\hline \multicolumn{5}{|c|}{ rs1004446_A (INS) } \\
\hline No & $2946(39.5)$ & $84(52.5)$ & $73(49.0)$ & \multirow[t]{2}{*}{0.538} \\
\hline Yes & $4521(60.5)$ & $76(47.5)$ & $76(51.0)$ & \\
\hline \multicolumn{5}{|c|}{ rs2476601_A (PTPN22) } \\
\hline No & $5979(80.1)$ & $102(63.8)$ & $102(68.5)$ & \multirow[t]{2}{*}{0.383} \\
\hline Yes & $1488(19.9)$ & $58(36.3)$ & $47(31.5)$ & \\
\hline \multicolumn{5}{|l|}{ rs10517086_A } \\
\hline No & $3839(51.4)$ & $62(38.8)$ & $73(49.0)$ & \multirow[t]{2}{*}{0.070} \\
\hline Yes & $3628(48.6)$ & $98(61.3)$ & $76(51.0)$ & \\
\hline \multicolumn{5}{|c|}{ rs2292239_T (ERBB3) } \\
\hline No & $3438(46.0)$ & $52(32.5)$ & $67(45.0)$ & \multirow[t]{2}{*}{0.024} \\
\hline Yes & $4028(54.0)$ & $108(67.5)$ & $82(55.0)$ & \\
\hline \multicolumn{5}{|c|}{ rs3184504_T (SH2B3) } \\
\hline No & $2314(31.0)$ & $41(25.6)$ & $43(28.9)$ & \multirow[t]{2}{*}{0.523} \\
\hline Yes & $5153(69.0)$ & $119(74.4)$ & $106(71.1)$ & \\
\hline \multicolumn{5}{|c|}{ rs12708716_G (CLEC16A) } \\
\hline No & $3278(44.0)$ & $78(48.8)$ & $82(55.0)$ & \multirow[t]{2}{*}{0.269} \\
\hline Yes & $4170(56.0)$ & $82(51.3)$ & $67(45.0)$ & \\
\hline rs 3825932_T $(C 7$ & & & & \\
\hline No & 3079 (41.2) & $80(50.0)$ & $75(50.3)$ & 0.953 \\
\hline Yes & $4387(58.8)$ & $80(50.0)$ & 74 (49.7) & \\
\hline
\end{tabular}


Table 1 (continued)

\begin{tabular}{|c|c|c|c|c|}
\hline Characteristic & $\begin{array}{l}\text { No type } 1 \\
\text { diabetes } \\
(n=8174)\end{array}$ & $\begin{array}{l}\text { Type } 1 \text { diabetes before } \\
6 \text { years } \\
\text { of age }(n=168)\end{array}$ & $\begin{array}{l}\text { Type } 1 \text { diabetes } \\
\geq 6 \text { years } \\
\text { of age }(n=160)\end{array}$ & $\begin{array}{l}p \\
\text { value }^{\mathrm{a}}\end{array}$ \\
\hline \multicolumn{5}{|c|}{ rs7111341_T (INS) } \\
\hline No & $4031(54.0)$ & $104(65.0)$ & $91(61.1)$ & \multirow[t]{2}{*}{0.475} \\
\hline Yes & $3436(46.0)$ & $56(35.0)$ & $58(38.9)$ & \\
\hline \multicolumn{5}{|c|}{ rs11711054_G (CCR5) } \\
\hline No & $3694(49.5)$ & $65(40.6)$ & $69(46.3)$ & \multirow[t]{2}{*}{0.314} \\
\hline Yes & $3765(50.5)$ & $95(59.4)$ & $80(53.7)$ & \\
\hline \multicolumn{5}{|c|}{ rs428595_A (PPIL2) } \\
\hline No & $7134(96.4)$ & $145(91.8)$ & $133(92.4)$ & \multirow[t]{2}{*}{0.850} \\
\hline Yes & $266(3.6)$ & $13(8.2)$ & $11(7.6)$ & \\
\hline \multicolumn{5}{|c|}{ rs113306148_T (PLEKHAI) } \\
\hline No & $7277(97.5)$ & $149(93.1)$ & $140(94.0)$ & \multirow[t]{2}{*}{0.766} \\
\hline Yes & $190(2.5)$ & $11(6.9)$ & $9(6.0)$ & \\
\hline \multicolumn{5}{|c|}{ rs73043122_C (RNASET2) } \\
\hline No & $7263(97.3)$ & $151(95.0)$ & $139(93.3)$ & \multirow[t]{2}{*}{0.530} \\
\hline Yes & $202(2.7)$ & $8(5.0)$ & $10(6.7)$ & \\
\hline \multicolumn{5}{|c|}{ Age at type 1 diabetes diagnosis (years) } \\
\hline$n$ & & 168 & 160 & \\
\hline Mean (SD) & & $3.3(1.5)$ & $8.9(1.8)$ & \\
\hline Median (IQR) & & $3.1(2.0-4.6)$ & $8.7(7.5-10.1)$ & $<0.001$ \\
\hline
\end{tabular}

Age at persistent confirmed autoantibody (years)

$\begin{array}{lllll}n & 499 & 154 & 138 & \\ \text { Mean (SD) } & 5.1(3.1) & 1.5(0.8) & 3.5(2.4) & \\ \text { Median (IQR) } & 4.6(2.3-7.7) & 1.2(0.8-1.8) & 2.6(1.9-4.5) & <0.001\end{array}$

Duration of time between first-appearing autoantibody and diagnosis (years)

$n$ 154

Mean (SD)

$1.9(1.4)$

$5.4(2.5)$

Median (IQR)

$1.6(0.6-2.9)$

$5.4(3.9-6.8)$

$<0.001$

Age at multiple persistent confirmed autoantibodies (years)

$\begin{array}{lllll}n & 208 & 133 & 121 & \\ \text { Mean (SD) } & 5.7(3.0) & 1.8(0.9) & 3.9(2.1) & \\ \text { Median (IQR) } & 5.5(3.1-8.4) & 1.5(1.1-2.2) & 3.3(2.3-5.1) & <0.001\end{array}$

Duration of time between multiple appearing autoantibodies and diagnosis (years)

$n$

Mean (SD)

Median (IQR)

Autoantibody status at seroconversion

\begin{tabular}{|c|c|c|c|c|}
\hline None & 7675 (93.9) & $14(8.3)$ & $22(13.8)$ & 0.001 \\
\hline GADA only & $272(3.3)$ & $31(18.5)$ & 43 (26.9) & \\
\hline IA2A only & $11(0.1)$ & $0(0.0)$ & $10(6.3)$ & \\
\hline IAA only & $174(2.1)$ & $75(44.6)$ & $45(28.1)$ & \\
\hline GADA, IA2A & $5(0.1)$ & $1(0.6)$ & $3(1.9)$ & \\
\hline GADA, IAA & $29(0.4)$ & $36(21.4)$ & $29(18.1)$ & \\
\hline IA2A, IAA & $4(0.0)$ & $1(0.6)$ & $2(1.3)$ & \\
\hline $\begin{array}{l}\text { GADA, IA2A, } \\
\text { IAA } \\
\text { ersistent confirm }\end{array}$ & $4(0.0)$ & $10(6.0)$ & $6(3.8)$ & \\
\hline \multicolumn{2}{|l|}{ No } & $50(29.8)$ & $45(28.1)$ & 0.744 \\
\hline \multicolumn{2}{|l|}{ Yes } & $118(70.2)$ & $115(71.9)$ & \\
\hline
\end{tabular}


Table 1 (continued)

\begin{tabular}{|c|c|c|c|c|}
\hline Characteristic & $\begin{array}{l}\text { No type } 1 \\
\text { diabetes } \\
(n=8174)\end{array}$ & $\begin{array}{l}\text { Type } 1 \text { diabetes before } \\
6 \text { years } \\
\text { of age }(n=168)\end{array}$ & $\begin{array}{l}\text { Type } 1 \text { diabetes } \\
\geq 6 \text { years } \\
\text { of age }(n=160)\end{array}$ & $\begin{array}{l}p \\
\text { value }^{\mathrm{a}}\end{array}$ \\
\hline \multicolumn{5}{|c|}{ Persistent confirmed IAA before or at type 1 diabetes diagnosis } \\
\hline No & & $22(13.1)$ & $46(28.8)$ & \multirow[t]{2}{*}{$<0.001$} \\
\hline Yes & & $146(86.9)$ & $114(71.3)$ & \\
\hline \multicolumn{5}{|c|}{ Persistent confirmed IA2A before or at type 1 diabetes diagnosis } \\
\hline No & & $64(38.1)$ & $46(28.8)$ & \multirow[t]{2}{*}{0.073} \\
\hline Yes & & $104(61.9)$ & $114(71.3)$ & \\
\hline \multicolumn{5}{|c|}{ Persistent confirmed ZnT8A before or at type 1 diabetes diagnosis } \\
\hline No & & $104(61.9)$ & $55(34.4)$ & \multirow[t]{2}{*}{$<0.001$} \\
\hline Yes & & $64(38.1)$ & $105(65.6)$ & \\
\hline \multicolumn{5}{|c|}{ DKA at type 1 diabetes diagnosis } \\
\hline No & & $151(89.9)$ & $153(95.6)$ & \multirow[t]{2}{*}{0.046} \\
\hline Yes & & $17(10.1)$ & $7(4.4)$ & \\
\hline \multicolumn{5}{|c|}{ Symptomatic at type 1 diabetes diagnosis } \\
\hline No & & $68(40.5)$ & $76(47.5)$ & \multirow[t]{2}{*}{0.200} \\
\hline Yes & & $100(59.5)$ & $84(52.5)$ & \\
\hline
\end{tabular}

Data are presented as number (percentage) unless otherwise indicated

For each SNP, the minor allele is indicated and data are divided by children with (yes) and without this allele (no) ${ }^{a} p$ value of comparing each characteristic between individuals with type 1 diabetes before 6 years of age and individuals with type 1 diabetes $\geq 6$ years of age. Wilcoxon's rank tests were performed for continuous variables and $\chi^{2}$ tests were performed for categorical variables

${ }^{\mathrm{b}}$ FDR-specific HLA-DR-DQ genotypes are DR4/4b, DR4/1, DR4/13, DR4/9, and DR3/9

the rate of progression to type 1 diabetes in the group who initially developed autoantibodies at an older age (hazard rate range from 0.072 to 0.116 ) irrespective of the age of seroconversion. Additionally, the rate of progression from multiple autoantibodies to type 1 diabetes was statistically associated with a family history of type 1 diabetes in the younger age group, but not in the older age group ( $p=0.25$, Fig. $3 b$ ).

Age at the onset of multiple autoantibodies, as a continuous variable, was also included in the analysis to explore whether the age groupings introduced artificial associations when comparing risk factors for early type 1 diabetes onset compared with later type 1 diabetes onset. Age at the onset of multiple autoantibodies was a highly significant factor in each age group (HR $0.56,95 \%$ CI $0.45,0.70, p<0.001$ and HR $0.83,95 \%$ CI $0.75,0.91, p<0.001$ ) showing decreasing risk with increasing age in both. After adjusting for the age at the development of multiple autoantibodies, the only remaining type 1 diabetes risk factors were family history of type 1 diabetes (father with type 1 diabetes vs those without family history of type 1 diabetes in the younger age group and mother or sibling with type 1 diabetes vs those without this type 1 diabetes family history in the older age group), and rs1004446_A (INS) (HR 0.55, $p=0.001$ ), rs428595_A (PPIL2) (HR 1.88, $p=0.043$ ) and rs10517086_A (HR 1.45, $p=0.033$ ) in the younger age group and rs3825932_T $(C T S H)$ (HR 0.57, $p=0.002)$, rs428595_A (PPIL2) (HR 1.97, $p$
$=0.044)$ and rs73043122_C $($ RNASET2) $(\mathrm{HR} 2.70, p=0.008)$ in the older age group.

\section{Discussion}

The proportion of children who were diagnosed with type 1 diabetes differed by geography between the younger and older age groups, despite the commonality of the high-risk genotypes across the TEDDY sites. Life-table analysis revealed that, over time, diabetes risk among the younger children residing in Finland was greatest, but declined proportionally as the children got older. Diabetes risk in the other sites remained relatively constant; the USA together with Sweden and Finland together with Germany were comparable, but the two country pairs were different. Older children more often presented with GADA as the first-appearing autoantibody and had a different HLA genotype (significantly less HLA DR3/3) than those who developed type 1 diabetes at an earlier age who predominantly presented with IAA as the firstappearing autoantibody. The number of children presenting with IAA as the first-appearing autoantibody declined with increasing age, whereas the incidence of GADA as the firstappearing autoantibody remained relatively constant over the age range. These results confirm earlier findings [e.g., the 

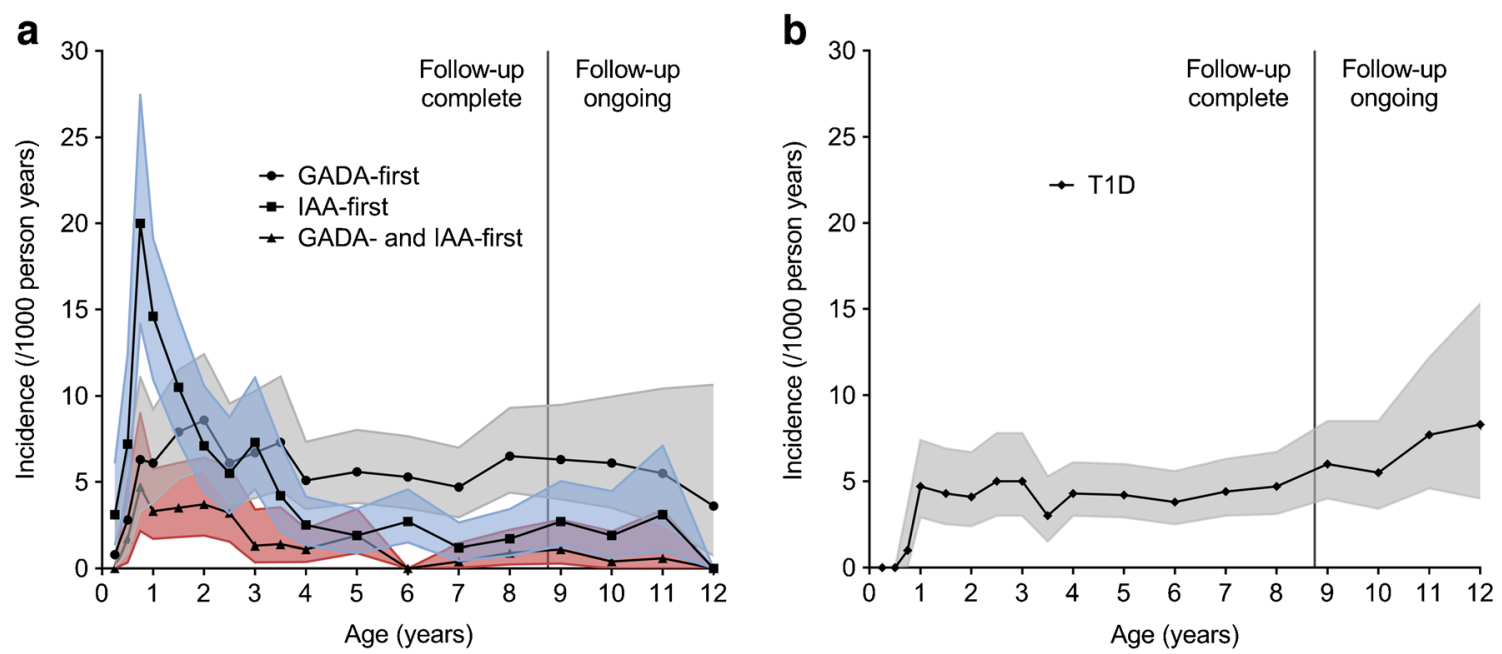

Fig. 1 Type 1 diabetes incidence by age-specific incidence of islet cell autoantibodies (a) and type 1 diabetes (b). T1D, type 1 diabetes

German BABYDIAB study [15], and the Finnish DIPP study $[16,17]]$ even in this HLA-defined high-risk population.

A new finding was that diabetes risk after the appearance of multiple autoantibodies did not differ between type 1 diabetesaffected and unaffected families, nor did the relationship of the affected family member to the TEDDY child. Initial seroconversion before 2 years of age was accompanied by higher diabetes risk after the appearance of multiple autoantibodies, but in children whose initial seroconversion to autoantibody positive was after 2 years of age, the risk did not decrease with increasing age of initial seroconversion. To complete the picture, the risk of initial seroconversion and progression to multiple autoantibodies decreased with increasing age, but once multiple autoantibodies were detected, the risk of progression did not decline with increasing age at seroconversion. Coupled with the changing picture of autoantibody presentation, it appears that autoimmunity at an early age is a more aggressive form of the disease.

These results underline the importance of taking into account the age at development of multiple autoantibodies when evaluating risk factors for progression to diabetes diagnosis. The HLA genotype, most SNPs, and family history were not significantly associated with early vs late diabetes diagnosis when taking into account the age at seroconversion to multiple autoantibodies. The implication is that they are risk factors for islet autoimmunity, but not necessarily for progression to diabetes once multiple autoantibodies have been observed.
Fig. 2 Kaplan-Meier curve of type 1 diabetes (across all ages) by country of origin $(p=0.0009$ from logrank test). T1D, type 1 diabetes

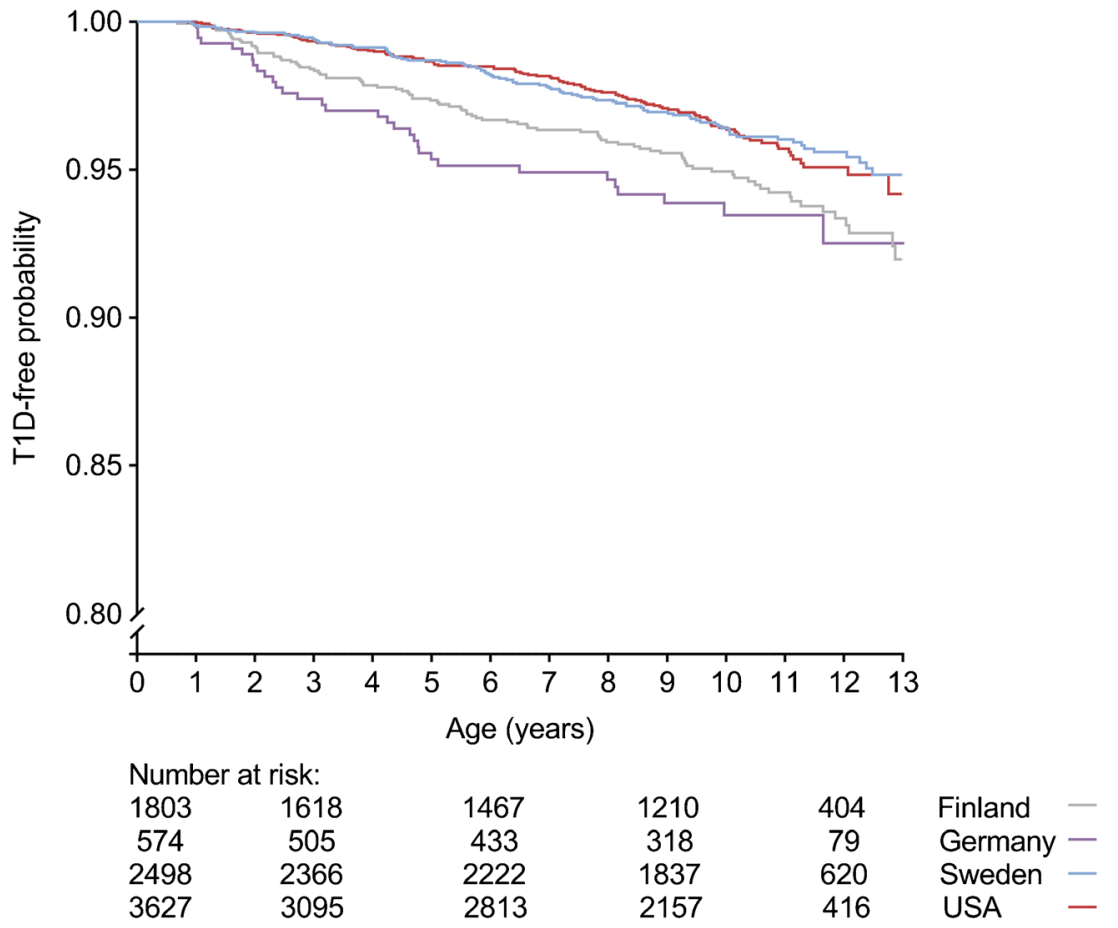


Table 2 HR, adjusted for covariates from the multiple PH analysis, of TEDDY published risk factors for type 1 diabetes

Type 1 diabetes before 6 Type 1 diabetes $\geq 6$ years years of age

\begin{tabular}{|c|c|c|c|c|c|c|}
\hline Factor & Comparison & HR $(95 \%$ CI) & $p$ value & HR $(95 \% \mathrm{CI})$ & $p$ value & $p$ value $^{\mathrm{a}}$ \\
\hline Sex & Male vs female & $1.06(0.77,1.46)$ & 0.715 & $1.12(0.80,1.57)$ & 0.507 & 0.819 \\
\hline Family history of type 1 & FDR mother vs GP & $1.51(0.75,3.05)$ & 0.249 & $2.64(1.36,5.12)$ & 0.004 & 0.256 \\
\hline \multirow[t]{2}{*}{ Diabetes } & FDR father vs GP & $3.24(1.99,5.26)$ & $<0.001$ & $2.41(1.31,4.41)$ & 0.005 & 0.452 \\
\hline & FDR sibling vs GP & $4.55(2.40,8.62)$ & $<0.001$ & $5.13(2.69,9.80)$ & $<0.001$ & 0.795 \\
\hline \multirow[t]{4}{*}{ HLA genotype } & DR4/4 vs DR3/3 & $1.26(0.65,2.44)$ & 0.496 & $4.16(1.99,8.69)$ & $<0.001$ & 0.018 \\
\hline & DR3/4 vs DR3/3 & $2.79(1.63,4.77)$ & $<0.001$ & $4.40(2.19,8.82)$ & $<0.001$ & 0.311 \\
\hline & DR $4 / 8$ vs DR3/3 & $1.50(0.77,2.93)$ & 0.237 & $3.36(1.52,7.45)$ & 0.003 & 0.127 \\
\hline & FDR-specific ${ }^{\mathrm{b}}$ vs DR3/3 & $1.60(0.69,3.70)$ & 0.269 & $1.29(0.38,4.44)$ & 0.683 & 0.777 \\
\hline \multirow[t]{3}{*}{ Country } & Finland vs USA & $3.20(1.88,5.45)$ & $<0.001$ & $1.26(0.73,2.18)$ & 0.416 & 0.005 \\
\hline & Germany vs USA & $2.19(1.27,3.78)$ & 0.005 & $0.56(0.25,1.27)$ & 0.167 & 0.007 \\
\hline & Sweden vs USA & $1.20(0.76,1.89)$ & 0.436 & $0.72(0.47,1.09)$ & 0.123 & 0.098 \\
\hline Probiotics introduction age & $<28$ days vs $\geq 28$ days & $0.86(0.49,1.51)$ & 0.606 & $0.94(0.46,1.94)$ & 0.871 & 0.852 \\
\hline Weight at 12 months & z-score & $1.10(0.94,1.30)$ & 0.223 & $1.21(1.03,1.44)$ & 0.024 & 0.426 \\
\hline \multirow[t]{4}{*}{ Child conditions before first clinical visit (age 3 months) } & Upper resp. (Yes vs No) & $1.43(1.00,2.04)$ & 0.053 & $1.00(0.67,1.50)$ & 0.999 & 0.198 \\
\hline & Lower resp. (Yes vs No) & $0.85(0.49,1.45)$ & 0.545 & $1.24(0.75,2.04)$ & 0.408 & 0.314 \\
\hline & Diarrhoea & $1.01(0.57,1.80)$ & 0.973 & $0.87(0.45,1.67)$ & 0.672 & 0.733 \\
\hline & Rash (Yes vs No) & $0.66(0.42,1.04)$ & 0.076 & $0.93(0.62,1.41)$ & 0.747 & 0.275 \\
\hline rs1004446_A (INS) & Yes vs No & $0.67(0.48,0.92)$ & 0.014 & $0.67(0.48,0.95)$ & 0.022 & 0.964 \\
\hline rs2476601_A (PTPN22) & Yes vs No & $2.04(1.46,2.84)$ & $<0.001$ & $1.72(1.20,2.47)$ & 0.003 & 0.503 \\
\hline rs10517086_A & Yes vs No & $1.48(1.07,2.05)$ & 0.019 & $1.04(0.75,1.45)$ & 0.808 & 0.141 \\
\hline rs2292239_T (ERBB3) & Yes vs No & $1.67(1.19,2.34)$ & 0.003 & $1.06(0.76,1.48)$ & 0.740 & 0.063 \\
\hline rs3184504_T(SH2B3) & Yes vs No & $1.23(0.85,1.77)$ & 0.275 & $1.07(0.74,1.55)$ & 0.731 & 0.599 \\
\hline rs12708716_G $(C L E C 16 A)$ & Yes vs No & $0.82(0.60,1.13)$ & 0.222 & $0.64(0.46,0.89)$ & 0.009 & 0.287 \\
\hline rs3825932_T $(C T S H)$ & Yes vs No & $0.76(0.55,1.04)$ & 0.087 & $0.66(0.47,0.93)$ & 0.017 & 0.581 \\
\hline rs7111341_T (INS) & Yes vs No & $0.68(0.48,0.96)$ & 0.026 & $0.77(0.54,1.09)$ & 0.142 & 0.616 \\
\hline rs11711054_G (CCR5) & Yes vs No & $1.46(1.06,2.02)$ & 0.021 & $1.15(0.83,1.61)$ & 0.404 & 0.315 \\
\hline rs428595_A (PPIL2) & Yes vs No & $2.13(1.20,3.80)$ & 0.010 & $2.10(1.13,3.92)$ & 0.019 & 0.972 \\
\hline rs113306148_T (PLEKHAI) & Yes vs No & $2.34(1.25,4.38)$ & 0.008 & $2.21(1.07,4.57)$ & 0.032 & 0.908 \\
\hline rs73043122_C (RNASET2) & Yes vs No & $2.31(1.12,4.76)$ & 0.023 & $2.54(1.27,5.06)$ & 0.008 & 0.856 \\
\hline
\end{tabular}

7433 individuals with 296 type 1 diabetes events (155 in the first 6 years and 141 after 6 years of age) were included in the analysis because values of SNPs and/or weight at 12 months of age were missing. For each SNP, the minor allele is indicated and children with this allele (yes) were compared with children without it (no)

The top two principal components from the Immunochip SNP were included as covariates in the Cox PH model ${ }^{a} p$ value for comparing the HR in the first 6 years vs the HR after 6 years of age

${ }^{\mathrm{b}}$ FDR-specific HLA-DR-DQ genotypes are DR4/4b, DR4/1, DR4/13, DR4/9, and DR3/9

Lower resp. lower respiratory tract infection; Upper resp. upper respiratory tract infection

Type 1 diabetes risk factors were relatively consistent across the two age groups. Some reached statistical significance in one age group but not in the other, but the difference in HRs between the age groups was not statistically significant. This could be an artifact caused by the age groupings. Nonetheless, it showcases the caution that should be exercised when trying to generalise findings beyond the population actually studied. The other important consideration is that the strength (i.e., the magnitude of the estimate of the HR along with its statistical significance) is derived from a multivariate analysis, which, by definition, adjusts for all the variables considered in the model. Hence, the results reflect the additive or independent contribution of each variable considered after the contribution of all the other variables have been considered. Hence, findings that are nonsignificant, or only marginally significant, might be completely different if all the variables in the model were independent (uncorrelated).

This study is not without limitations. The characteristics of children who develop type 1 diabetes in the TEDDY study 

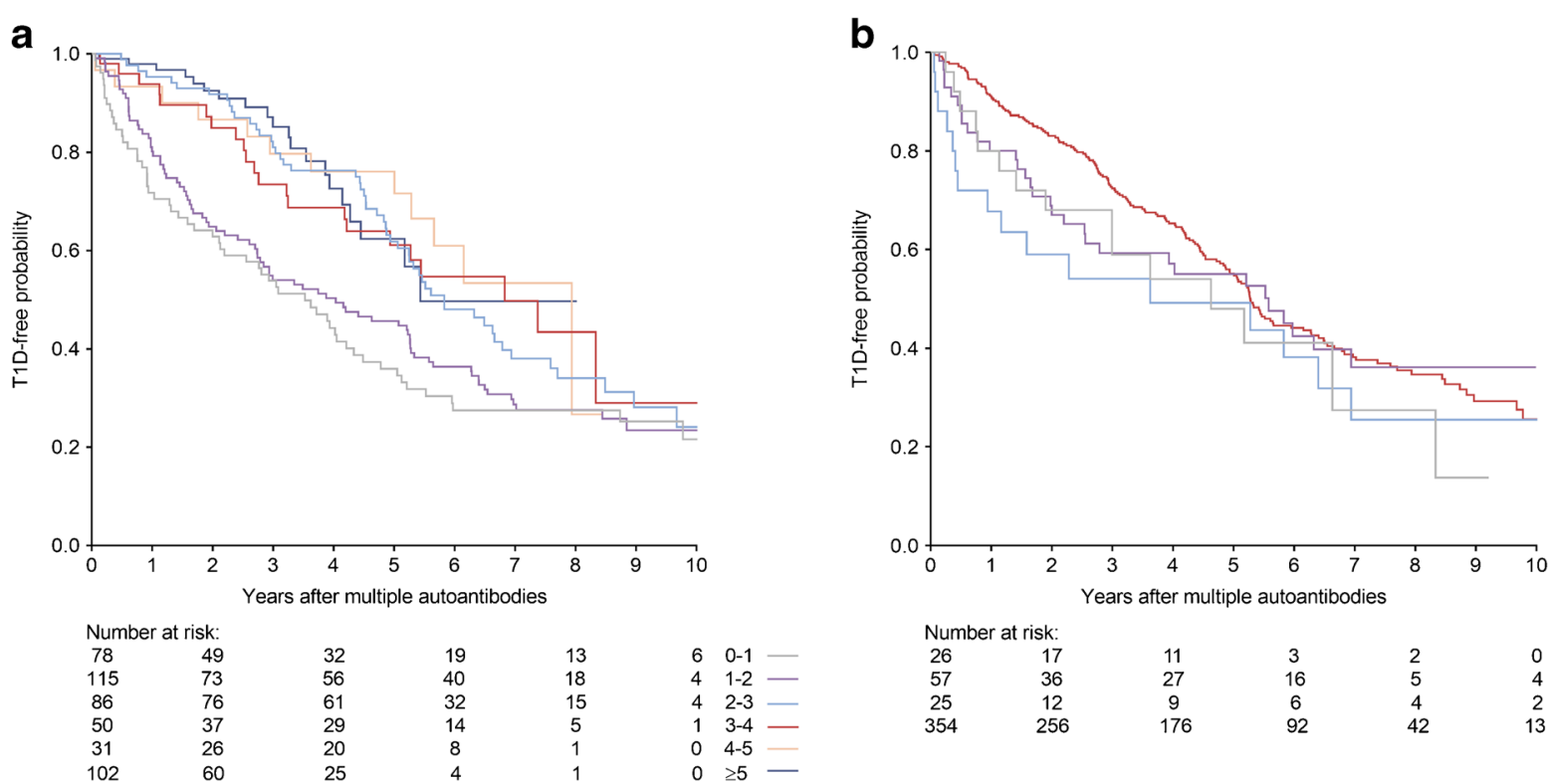

\begin{tabular}{|c|c|c|c|c|c|c|c|}
\hline \multicolumn{8}{|c|}{ Number at risk: } \\
\hline \multicolumn{8}{|c|}{$26 \quad 17$} \\
\hline 57 & 36 & 27 & 16 & 5 & 4 & FDR father & - \\
\hline 25 & 12 & 9 & 6 & 4 & 2 & FDR sibling & - \\
\hline 354 & 256 & 176 & 92 & 42 & 13 & $\mathrm{GP}$ & _ \\
\hline
\end{tabular}

Fig. 3 Type 1 diabetes risk since developing multiple autoantibodies by (a) age of initial seroconversion and (b) family history of type 1 diabetes. T1D, type 1 diabetes

might not be generalisable to other HLA-defined populations. Despite this study's size of 8502 children, there are still relatively few type 1 diabetes cases. Yet, the before and after age 6 groups consist of nearly exactly the same number of children. This suggest that differences between the two age-defined cohorts were not due to an imbalance in the numbers.

The predominance of IAA first as the single presenting autoantibody in the very young age group compared with the predominance of GADA first as the single presenting autoantibody in the older age groups is entirely consistent with the observed age-related association of exposures and both HLA and non-HLA genotypes. However, caution should be exercised in generalising the results presented here beyond the age range in which they have been discovered and the selected high-risk HLA subgroups that make up the TEDDY population. Yet, the TEDDY children represent, depending on country, about 40 $50 \%$ of children expected to develop diabetes before 18 years of age [3]. The age at screening for the presence of islet autoantibodies in both the general population or among FDRs and its associated heterogeneity with respect to diabetes risk factors $[18$, 19] should be taken into account when individuals are randomised in secondary prevention studies of type 1 diabetes.

Finally, the report of study findings in a large epidemiological study, like TEDDY, involves many statistical comparisons, increasing the chance of spurious findings. In our opinion, using multivariate analyses to incorporate adjustments is a practical approach to this issue, whereas adjusting the significance threshold for multiple comparisons is not. There are arguments to be made for and against these approaches [20-22]. We have chosen to not make adjustments for multiple comparisons and advise readers to consider these findings in the context of the published literature on similar populations.
Supplementary Information The online version contains peer-reviewed but unedited supplementary material available at https://doi.org/10.1007/ s00125-021-05514-3.

Acknowledgements The authors thank Sarah Austin-Gonzalez with the Health Informatics Institute at the University of South Florida for assistance with preparing the figures.

A special acknowledgement to the TEDDY families for their continued participation in this wonderful study.

Data availability The datasets generated and analysed during the current study will be made available in the NIDDK Central Repository at https://www.niddkrepository.org/studies/teddy.

Funding Funded by U01 DK63829, U01 DK63861, U01 DK63821, U01 DK63865, U01 DK63863, U01 DK63836, U01 DK63790, UC4 DK63829, UC4 DK63861, UC4 DK63821, UC4 DK63865, UC4 DK63863, UC4 DK63836, UC4 DK95300, UC4 DK100238, UC4 DK106955, UC4 DK112243, UC4 DK117483, U01 DK124166 and Contract No. HHSN267200700014C from the National Institute of Diabetes and Digestive and Kidney Diseases (NIDDK), National Institute of Allergy and Infectious Diseases (NIAID), Eunice Kennedy Shriver National Institute of Child Health and Human Development (NICHD), National Institute of Environmental Health Sciences (NIEHS), JDRF, and Centers for Disease Control and Prevention (CDC). This work supported in part by the NIH/NCATS Clinical and Translational Science Awards to the University of Florida (UL1 TR000064) and the University of Colorado (UL1 TR002535).

Duality of interest There are no conflicts of interest.

Contribution statement All authors attest to meeting ICMJE uniform requirements for authorship by making substantial contributions to conception and design of this paper; acquisition, analysis and interpretation of the data; drafting or revising the article for intellectual content; and giving final approval of the published version. JK designed the study, proposed the analysis, interpreted the findings, and wrote the manuscript. XL performed the analysis and contributed to writing the manuscript. ÅL, WH, MR, J-XS, JT, 
AZ, and BA designed the study and reviewed/edited the manuscript. JK and $\mathrm{XL}$ are the guarantors of this work and, as such, had full access to all the data in the study and take responsibility for the integrity of the data and the accuracy of the data analysis. The authors declare that there are no relationships or activities that might bias, or be perceived to bias, their work.

\section{References}

1. TEDDY Study Group (2007) The Environmental Determinants of Diabetes in the Young (TEDDY) study: study design. Pediatr Diabetes 8:286-298. https://doi.org/10.1111/j.1399-5448.2007. 00269.x

2. TEDDY Study Group (2008) The Environmental Determinants of Diabetes in the Young (TEDDY) study. Ann N Y Acad Sci 1150: $1-13$

3. Hagopian WA, Erlich H, Lernmark Å, TEDDY Study Group et al (2011) The Environmental Determinants of Diabetes in the Young (TEDDY): genetic criteria and international diabetes risk screening of 421000 infants. Pediatr Diabetes 12:733-743. https://doi.org/10. 1111/j.1399-5448.2011.00774.x

4. Krischer JP, Lynch KF, Schatz DA, TEDDY Study Group et al (2015) The 6 year incidence of diabetes-associated autoantibodies in genetically at-risk children: the TEDDY study. Diabetologia 58: 980-987. https://doi.org/10.1007/s00125-015-3514-y

5. Krischer JP, Lynch KF, Lernmark Å, TEDDY Study Group et al (2017) Genetic and environmental interactions modify the risk of diabetes-related autoimmunity by 6 years of age: the TEDDY study. Diabetes Care 40:1194-1202. https://doi.org/10.2337/dc170238

6. Parkes M, Cortes A, van Heel DA, Brown MA (2013) Genetic insights into common pathways and complex relationships among immune-mediated diseases. Nat Rev Genet 14:661-673. https:// doi.org/10.1038/nrg3502

7. Törn C, Hadley D, Lee HS, TEDDY Study Group et al (2015) Role of type 1 diabetes associated SNPs on risk of autoantibody positivity in the TEDDY study. Diabetes 64:1818-1829. https://doi.org/ $10.2337 / \mathrm{db} 14-1497$

8. Bonifacio E, Yu L, Williams AK et al (2010) Harmonization of glutamic acid decarboxylase and islet antigen-2 autoantibody assays for national institute of diabetes and digestive and kidney diseases consortia. J Clin Endocrinol Metab 95:3360-3367. https:// doi.org/10.1210/jc.2010-0293

9. Lee HS, Burkhardt BR, McLeod W, the TEDDY Study Group et al (2014) Biomarker discovery study design for type 1 diabetes in the Environmental Determinants of Diabetes in the Young (TEDDY) study. Diabetes Metab Res Rev 30(5):424-434. https://doi.org/10. 1002/dmrr.2510

10. Uusitalo U, Lee HS, Andren Aronsson C, TEDDY Study Group et al (2018) Early infant diet and islet autoimmunity in the TEDDY study. Diabetes Care 41:522-530. https://doi.org/10.2337/dc171983
11. Elding Larsson H, Vehik K, Haller MJ, TEDDY Study Group et al (2016) Growth and risk for islet autoimmunity and progression to type 1 diabetes in early childhood: the Environmental Determinants of Diabetes in the Young Study. Diabetes 65:1988-1995. https:// doi.org/10.2337/db15-1180

12. Sharma A, Liu X, Hadley D, TEDDY Study Group et al (2018) Identification of non-HLA genes associated with development of islet autoimmunity and type 1 diabetes in the prospective TEDDY cohort. J Autoimmun 89:90-100. https://doi.org/10.1016/j.jaut. 2017.12.008

13. Cantor AB (2003) Extending SAS survival analysis techniques for medical research, 2nd ed. SAS Institute

14. Concannon P, Chen WM, Julier C et al (2009) Genome-wide scan for linkage to type 1 diabetes in 2,496 multiplex families from the Type 1 diabetes Genetics Consortium. Diabetes 58:1018-1022. https://doi.org/10.2337/db08-1551

15. Hummel M, Bonifacio E, Schmid S et al (2004) Brief communication: early appearance of islet autoantibodies predicts childhood type 1 diabetes in offspring of diabetic parents. Ann Intern Med 140:882-886. https://doi.org/10.7326/0003-4819-140-11200406010-00009

16. Bauer W, Veijola R, Lempainen J et al (2019) Age at seroconversion, HLA genotype and specificity of autoantibodies in progression of islet autoimmunity in childhood. J Clin Endocrinol Metab 104:4521-4530. https://doi.org/10.1210/jc.2019-00421

17. Ilonen J, Hammais A, Laine AP et al (2013) Patterns of $\beta$-cell autoantibody appearance and genetic associations during the first years of life. Diabetes 62:3636-3640. https://doi.org/10.2337/ db13-0300

18. Frederiksen BN, Kroehl M, Barón A et al (2015) Assessing agerelated etiologic heterogeneity in the onset of islet autoimmunity. Biomed Res Int 2015:708289. https://doi.org/10.1155/2015/ 708289

19. Xu P, Krischer JP, Type 1 Diabetes TrialNet Study Group (2016) Prognostic classification factors associated with development of multiple autoantibodies, dysglycemia, and type 1 diabetes-a recursive partitioning analysis. Diabetes Care 39:1036-1044. https://doi. org/10.2337/dc15-2292

20. Thompson JR (1998) Invited commentary: Re: "Multiple comparisons and related issues in the interpretation of epidemiologic data.”. Am J Epidemiol 147:801-806. https://doi.org/10.1093/ oxfordjournals.aje.a009530

21. Savitz DA, Olshan AF (1995) Multiple comparisons and related issues in the interpretation of epidemiologic data. Am J Epidemiol 142:904-908. https://doi.org/10.1093/oxfordjournals.aje.a117737

22. Savitz DA, Olshan AF (1998) Describing data requires no adjustment for multiple comparisons: a reply from Savitz and Olshan. Am J Epidemiol 147:813-814. https://doi.org/10.1093/oxfordjournals. aje.a009532

Publisher's note Springer Nature remains neutral with regard to jurisdictional claims in published maps and institutional affiliations. 